\title{
Vorwort zur ersten Auflage.
}

Der Verfasser unternimmt es, ein neues Gesamt-Gemälde des Wissensgebietes zu entwerfen, dessen Stoff zu mehren und dessen Probleme zu sichten er im Laufe mehrerer Jahrzehnte angelegentlich bestrebt war. Das auf drei Bände veranschlagte Werk, in welchem der Verfasser aus seiner Lebensarbeit die Summe zieht, soll den weiten Kreisen der Gebildeten zugänglich sein. Der Standpunkt, den er einnimmt, ist nicht der irgendeiner einseitigen und ausschließlichen Schule. Er bemüht sich, den verschiedenen antiken Denkrichtungen, von denen jede ihr Teil zu dem Gesamtbau der modernen Geistesbildung beigesteuert hat, gleichmäßig gerecht zu werden, sie allesamt unbefangen $\mathrm{zu}$ betrachten und billig $\mathrm{zu}$ beurteilen. Die Darstellung soll sich von einem nicht allzu dürftigen kulturhistorischen Hintergrund abheben und ein subjektives Gepräge nur insoweit tragen, als die Hervorhebung des Wesentlichen eine möglichst scharfe, die Scheidung des Bleibenden und Bedeutsamen von dem Gleichgültigen und Vergänglichen eine möglichst durchgreifende sein soll. Aus der Geschichte der Religion, der Literatur und der Einzelwissenschaften werden dem Werke solche Ausschnitte einverleibt werden, die für das Verständnis der spekulativen Bewegung, ihrer Ursachen und Wirkungen unentbehrlich sind. Die Grenzlinien, welche diese Gebiete trennen, erscheinen dem Verfasser durchweg als fließende. Das Ideal, das ihm vor Augen steht, ließe sich nur in einer erschöpfenden Gesamtgeschichte des antiken Geisteslebens vollständig verwirklichen. Der gelungenen Ausführung solch eines gewaltigen Unternehmens gegenüber wird der gegenwärtige, ungleich bescheidenere Versuch gern als überholt und veraltet gelten.

Der zweite Band soll gleich dem vorliegenden ersten aus drei Büchern bestehen, deren Aufschriften lauten werden: „Sokrates und 
die Sokratiker“, „Platon und die Akademie“, „Aristoteles und seine Nachfolger“. Der Schlußband soll über die „ältere Stoa“, über den „Garten Epikurs“ und über „Mystik, Skepsis und Synkretismus“ handeln.

Um den Umfang des Werkes nicht allzusehr anzuschwellen, mußten Quellen-Belege die knappste Gestalt annehmen und mußte mit Hinweisen auf die neuere Literatur überall gekargt werden, außer dort, wo die Darstellung des Verfassers am meisten, und dort, wo sie am wenigsten originell ist, wo ihm mithin die Verpflichtung erwächst, seine enge Abhängigkeit von Vorgängern zu bekennen oder seine tiefgreifende Abweichung von herkömmlichen Auffassungen zu begründen.

Schließlich mag es zur Entschuldigung, nicht nur zur Beschönigung der Mängel dieses Werkes seinem Verfasser erlaubt sein, sich ein Wort anzueignen, das einst $\mathrm{G} u \mathrm{stave} F \mathbf{F}$ a u e rt an George Sand geschrieben hat: „Je fais tout ce que je peux continuellement pour élargir ma cervelle et je travaille dans la sincérité de mon coeur; le reste ne dépend pas de moi."

W i e n, im September 1895.

\section{Vorwort zur zweiten Auflage.}

Die zweite Auflage unterscheidet sich nicht gar erheblich von der ersten. Einige kleinere Irrtümer werden berichtigt, ein paar Aufstellungen, die sich als unhaltbar erwiesen haben, sind getilgt und den Anmerkungen nicht allzu wenige Zusätze einverleibt worden. Diese beziehen sich zum größten Teil auf neu zutage gekommenes Quellenmaterial, wie denn der Fragmenten-Bestand des Heraklit, des Pherekydes und Demokrit durch einige, zum Teil sehr wichtige Funde der jüngsten Zeit bereichert worden ist. Inwieweit das in der Vorrede der ersten Auflage enthaltene Programm in der Ausführung modifiziert worden ist, ersieht der Leser aus dem Vorwort des zweiten Bandes.

W i e n, im Juli 1902. 